\title{
Clinical improvement and radiological progression in a girl with early onset scoliosis (EOS) treated conservatively - a case report Hans-Rudolf Weiss*
}

\author{
Address: Asklepios Katharina Schroth Spinal Deformities Rehabilitation Centre, Bad Sobernheim, Germany \\ Email: Hans-Rudolf Weiss* - hr.weiss@asklepios.com \\ * Corresponding author
}

Published: 26 July 2006

Scoliosis 2006, I:13 doi:10.1186/1748-7/61-1-13
Received: 25 May 2006

Accepted: 26 July 2006

This article is available from: http://www.scoliosisjournal.com/content/I/I/13

(C) 2006 Weiss; licensee BioMed Central Ltd.

This is an Open Access article distributed under the terms of the Creative Commons Attribution License (http://creativecommons.org/licenses/by/2.0), which permits unrestricted use, distribution, and reproduction in any medium, provided the original work is properly cited.

\begin{abstract}
Background: Chêneau-Brace treatment of a certain standard reduces the rate of surgery, prevents progression and in a certain patient population leads to marked improvement of Cobb angle and cosmetic appearance. During the last two years a patient refusing surgery with a double major curvature of initially $60^{\circ}$ showed a clear cosmetic improvement and a clear radiological progression at the same time. The findings of this patient have been reviewed in order to find out how cosmetic appearance and Cobb angle can develop differently.
\end{abstract}

Methods: The patient entered conservative treatment at the age of 13 years, premenarchial with Tanner II and a Cobb angle of $60^{\circ}$ thoracic and $59^{\circ}$ lumbar. The angle of trunk rotation (ATR; Scoliometer) was $13^{\circ}$ thoracic and $13^{\circ}$ lumbar. We have documented the findings of this patient (Surface topography, ATR, Cobb angles and angles of vertebral rotation (according to Raimondi) during the treatment period (27 Month) until 2 years after the onset of menarche.

Results: After a treatment time of 27 Month the Cobb angle increased to $74^{\circ}$ thoracic and $65^{\circ}$ lumbar. The angles of vertebral rotation according to Raimondi increased slightly from $26^{\circ}$ thoracic and $28^{\circ}$ lumbar to $30^{\circ}$ thoracic and $28^{\circ}$ lumbar. The ATR improved to $12^{\circ}$ thoracic and $5^{\circ}$ lumbar while Lateral deviation improved from $22,4 \mathrm{~mm}$ to $4,6 \mathrm{~mm}$ and average surface rotation improved from $10,6^{\circ}$ to $6^{\circ}$. In the X-rays a reduction of decompensation was visible. The patient felt comfortable with the cosmetic result.

Conclusion: Conservative treatment may improve cosmetic appearance while the curve progresses radiologically. This could be explained by assuming that (I) the Rigo Chêneau brace is able to improve cosmetic appearance by changing the shape of the thorax when the curve itself is too stiff to be corrected by a brace, that (2) reduction of decompensation leads to significant cosmetical improvements or (3) that the patient gained weight and therefore the deformation is masked. However, the weight the patient gained cannot explain the cosmetical improvement in this case.

Conservative treatment with a certain standard of quality seems a viable alternative for patients with Cobb angles of $>60^{\circ}$ when surgical treatment is refused.

Specialists in scoliosis management should be aware of the fact that curve progression can occur even if the clinical measurements show an improvement. 

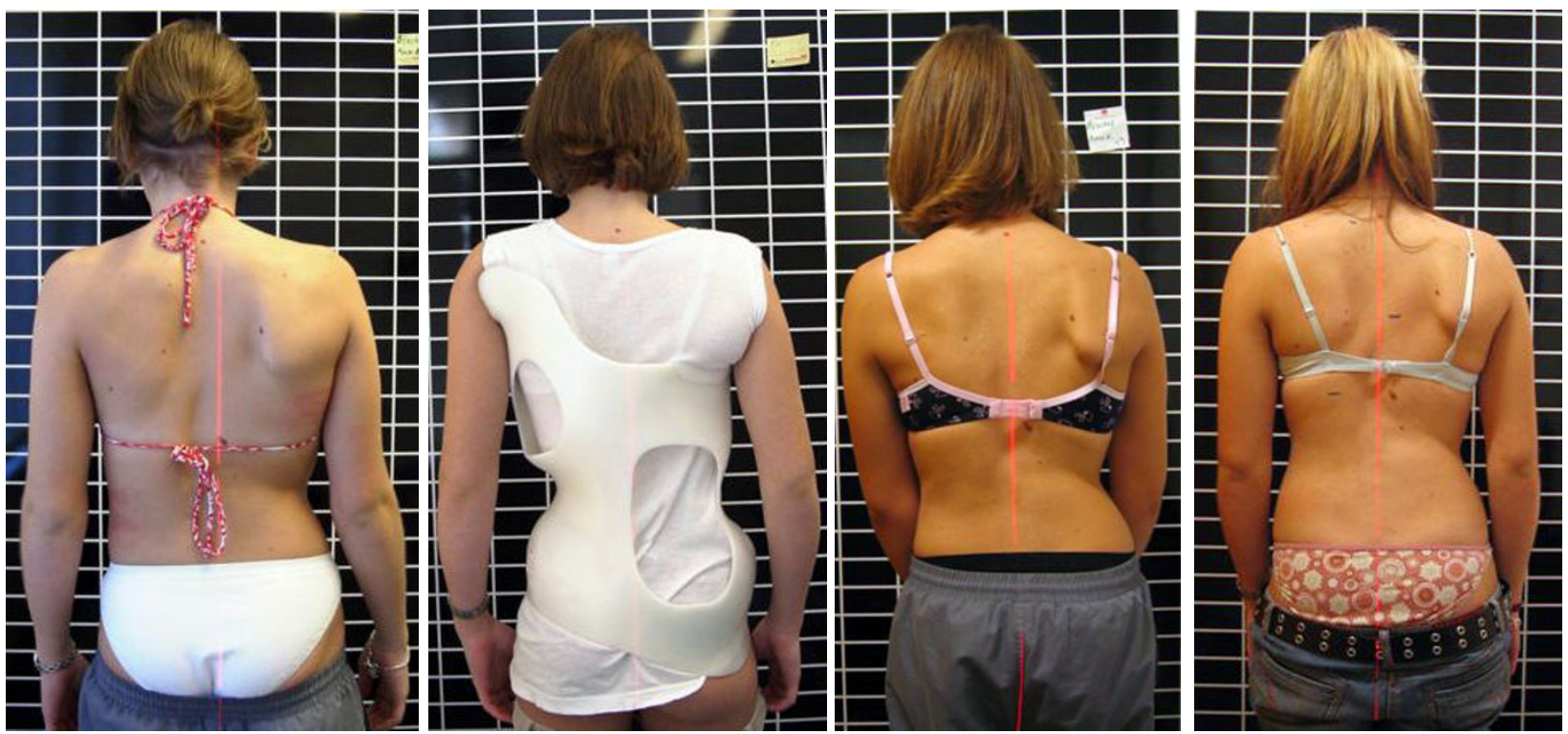

\section{Figure I}

Clinical history of the patient. On the left the patient can be seen at the start of treatment, on the middle left in the first brace, on the middle right clinically after one year of treatment and on the right after 27 months of treatment before the weaning brace was adjusted. A considerable cosmetic improvement can be seen comparing the picture at the start of treatment (left) to the picture two years after the onset of menarche (right).

\section{Background}

In Continental Europe [1-3] especially in Germany, a conservative treatment approach is pursued actively from the time of diagnosis [4-9]. In adolescence, this approach includes outpatient physiotherapy beginning at $15^{\circ}$ according to Cobb. Scoliosis intensive rehabilitation (SIR) is recommended for curvatures of $20^{\circ}$ to $30^{\circ}$, with or without bracing, depending on prognosis [10]. For adult Idiopathic Scoliosis (IS), outpatient physiotherapy is offered for curvatures of $30^{\circ}$ to $40^{\circ}$ [11-13] with moderate pain. Physiotherapists in different regions are trained, so that patients have the option of continued outpatient treatment close to their residence. For adult patients with curves over $40^{\circ}$ in association with cardio-respiratory functional impairment and pain, SIR is recommended. Inpatient treatment offers structure for a daily six-hour intensive rehabilitation treatment [11].

Two factors have emerged as the main parameters of successful brace treatment. Goldberg and co-workers [14] cite two references in which good patient compliance with bracing corresponded with favorable outcomes $[15,16]$. However, the actual extent of the corrective effect is also described as an essential criterion in successful bracing. Based on a review of the literature, we confirmed that there exists a direct positive correlation between the pri- mary corrective effect of an orthosis and the end result [17]. The importance of this effect is supported by a study from Mellerowicz et. al. [18] and by a study from Landauer [19], in which they independently conclude that compliance and the primary correction effect in the brace are the two most important variables associated with good brace outcomes.

The treatment of AIS however serves to change not only the secondary symptoms of scoliosis and the x-ray (Fig. 1 and 2) but - most important to the adolescent - also aims at an improvement of the cosmetic signs of the deformity $[10,14]$. Thulbourne and Gillespie [20] may be right in saying that even if the progression can be reduced by bracing, cosmetic appearance and the rib hump may not always be influenced positively, nor may a successful course as shown by X-ray always be appreciated as a successful treatment by the patient. The authors express their point of view as follows: Ever since the introduction of the Milwaukee brace, opinions have differed widely as to its effect on the rib hump. We are now able to state that in most cases the true rib hump on the convex side of a thoracic curve is little influenced, whereas the contralateral rib depression can be markedly reduced, and in the most responsive cases even completely corrected. Thus for patients where the rib depression contributes a disproportionate part of the total deformity, one may 

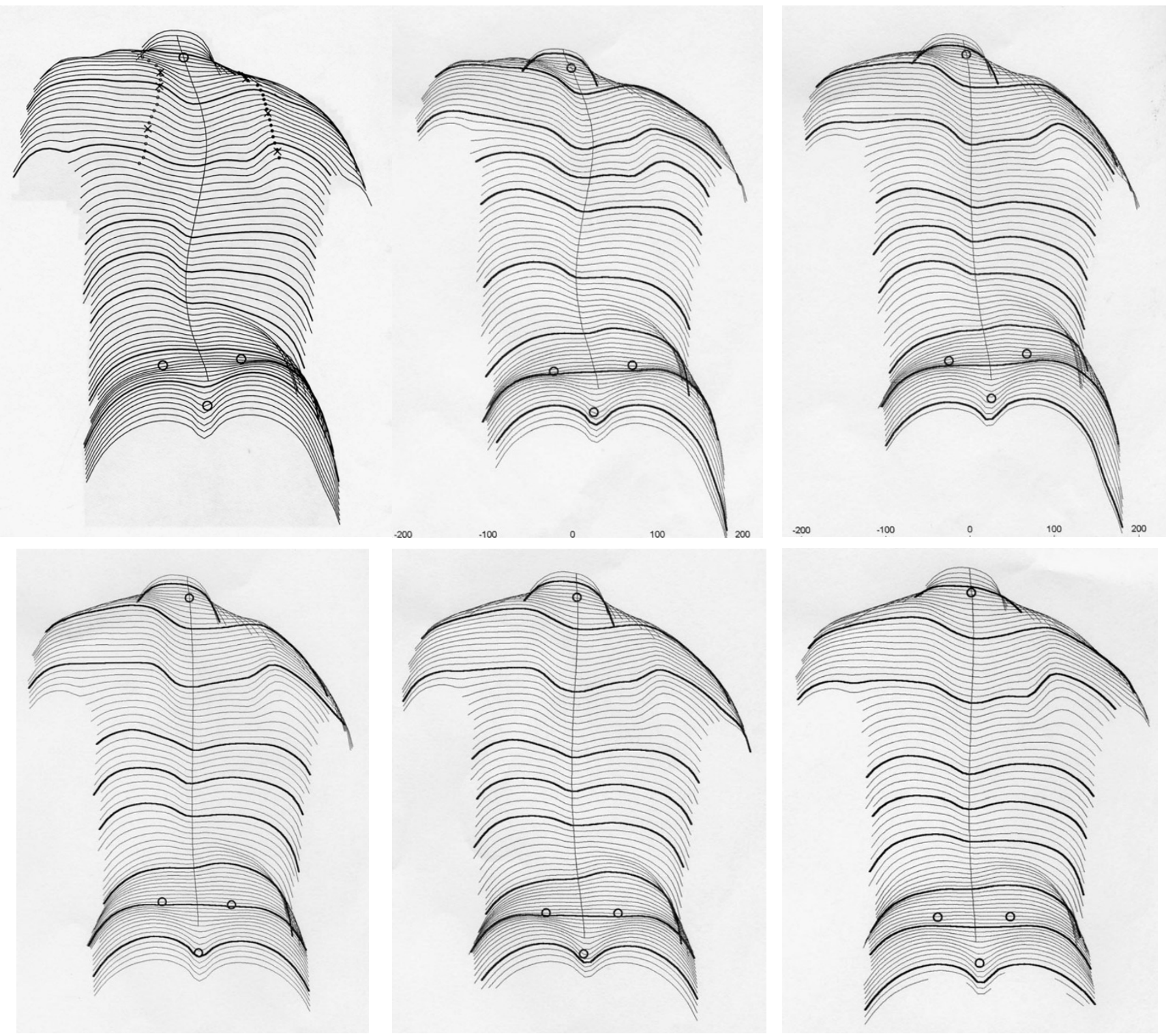

\section{Figure 2}

Clinical history of the patient as documented by surface topography. On the upper left the patients reconstructed back can be seen at the start of treatment, on the upper middle picture 6 months and on the upper right picture 12 months while treated with the brace. A little improvement is visible after 12 month of treatment. On the lower left the patients reconstructed back can be seen 15 month after the start of treatment, on the lower middle picture 20 months and on the lower right picture 27 months while treated. A clear cosmetic improvement is visible when the initial surface reconstruction (upper left) is compared to the last one on the lower right.

maintain a rather more optimistic view as to the ultimate clinical appearance than can be held when the hump is the more obvious feature [20].

Rigo however has demonstrated that the application of the Rigo-System Chêneau brace (RSC-Brace) leads to significant improvements of the cosmetic deformations
$[21,22]$ and to a significantly reduced rate of progression [23]. The frontal corrections in the RSC brace were at average about $30-40 \%$ for the major curve but also showed a significant reduction of vertebral rotation (22\%). So not only compliance and correction in frontal plane but also 3-D correction plays an important role in the conservative management with the help of braces. 

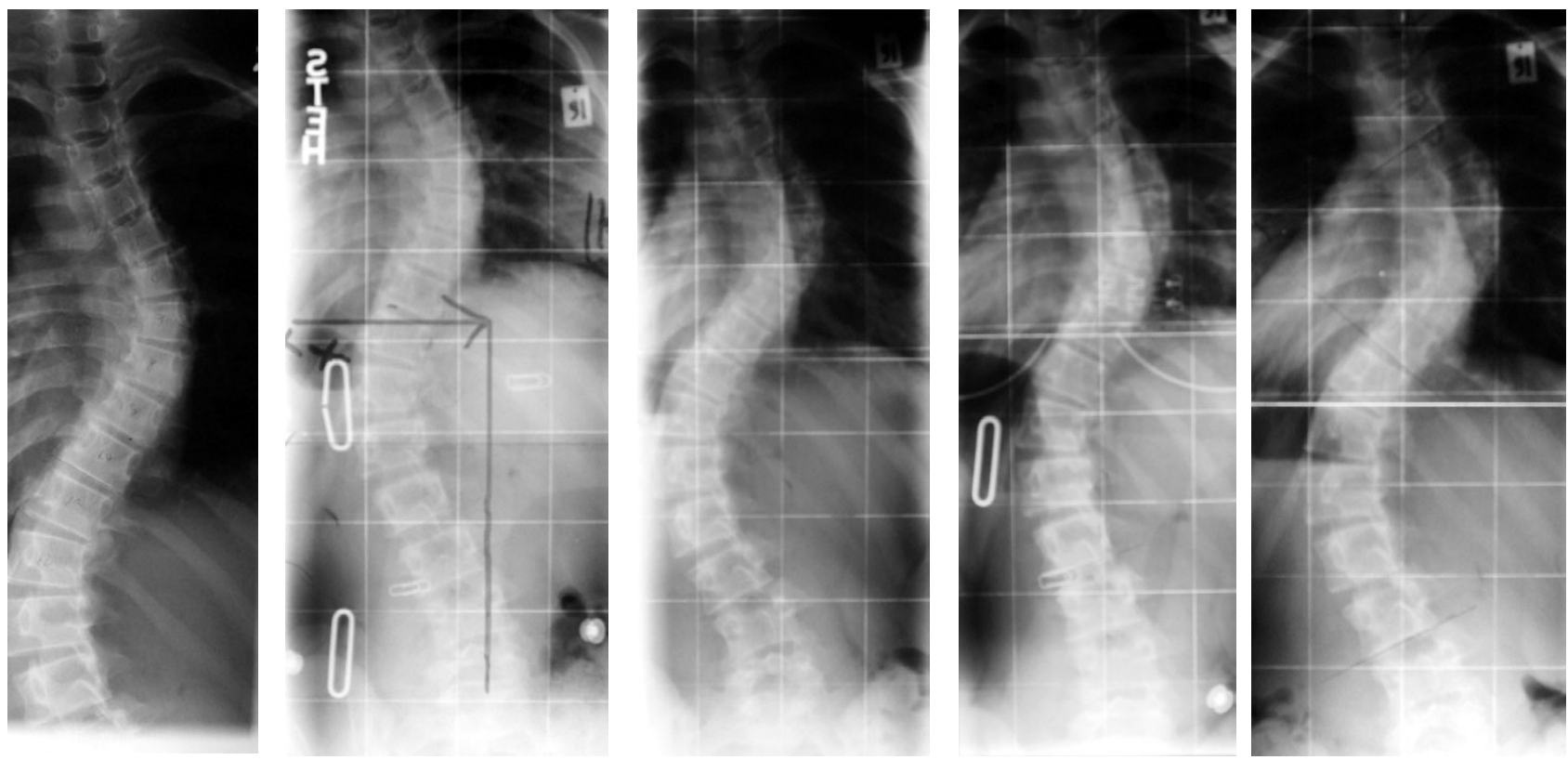

Figure 3

Radiological history of the patient. From left (x-ray taken outside our centre before start of treatment) to right the radiological course of the patient can be seen (last picture after 27 months on the right). A progression of the curve is visible.

Treatment of scoliosis with the Chêneau brace is currently the most practised conservative method in Germany, Austria, Spain, Greece as well as in Poland. It is also used in France and Italy. The Cheneau brace is defined as a thermoplastic brace modelled on a hyper-corrected positive plaster mould of the patient. Specific pad areas are designed to provide detorsional forces through the trunk. Expansion rooms are also provided, in order to allow active correction by breathing movements. Clinical histories of individuals enjoying excellent corrective effects and favorable outcomes with the Cheneau brace are encouraging its use in many places in Central Europe.

During the last two years a patient refusing surgery with a double major curvature of initially $60^{\circ}$ showed a clear cosmetic improvement and a clear progression at the same time while treated conservatively with out-patient exercises, in-patient rehabilitation and a Rigo-System Chêneau brace. The findings of this patient have been reviewed in order to find out how cosmetic appearance and Cobb angle can develop differently.

\section{Methods}

The patient with EOS (onset at the age of 6 years) entered conservative treatment (out-patient exercises, in-patient rehabilitation and the Chêneau brace) at the age of 13 years, premenarchial with Tanner II and a Cobb angle of $60^{\circ}$ thoracic and $59^{\circ}$ lumbar. The angle of trunk rotation (ATR; Scoliometer) was $13^{\circ}$ thoracic and $13^{\circ}$ lumbar. We have documented the findings of this patient (Surface topography, ATR, Cobb angles and angles of vertebral rotation according to Raimondi) during the treatment period (27 months) until 2 years after the onset of menarche.

\section{Results \\ Patient history}

After a treatment time of 27 months the Cobb angle increased to $74^{\circ}$ thoracic and $65^{\circ}$ lumbar. The angles of vertebral rotation according to Raimondi increased slightly from $26^{\circ}$ thoracic and $28^{\circ}$ lumbar to $30^{\circ}$ thoracic and $28^{\circ}$ lumbar.

The ATR improved to $12^{\circ}$ thoracic and $5^{\circ}$ lumbar while lateral deviation (as measured by surface topography) improved from $22,4 \mathrm{~mm}$ to $4,6 \mathrm{~mm}$ and average surface rotation improved from $10,6^{\circ}$ to $6^{\circ}$. In the X-ray an improvement of decompensation was visible. No change in curve pattern occurred. The patient felt comfortable with the cosmetic result. She gained 23 of 24 points in the Bad Sobernheim Stress Questionnaire (BSSQ) which means she feels only very little stress with respect to her deformity of the trunk [24], while she was very concerned at her first presentation. 
ATR Scoliometer angle of the thoracic curve during the treatment time of 27 month

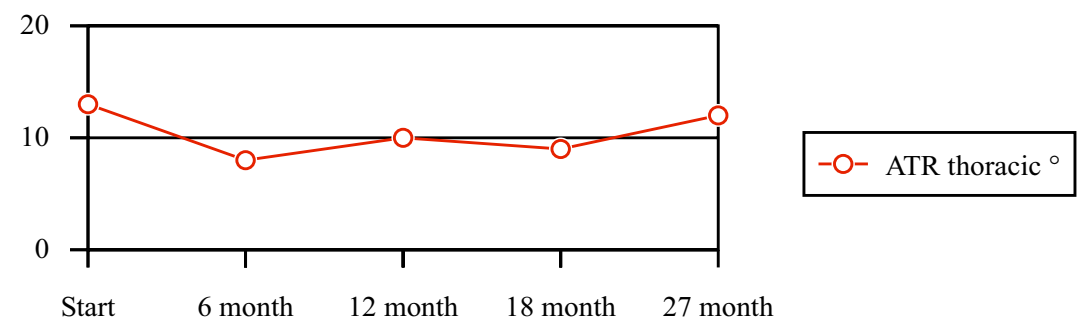

ATR Scoliometer angle of the lumbar curve during the treatment time of 27 month

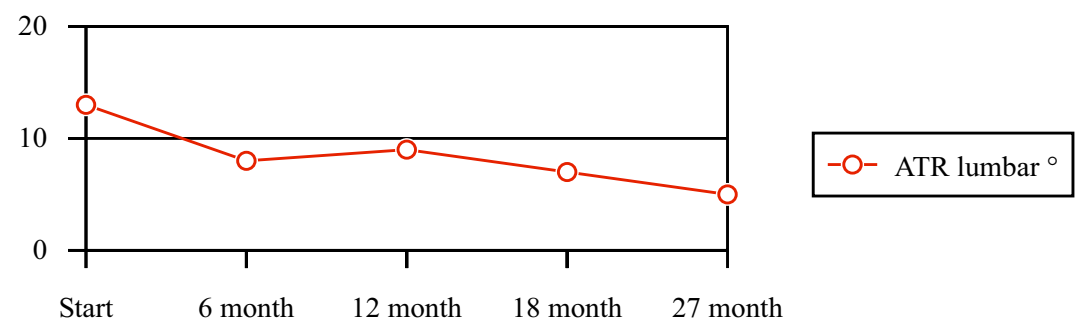

Lateral deviation (rms) during the treatment time of 27 month

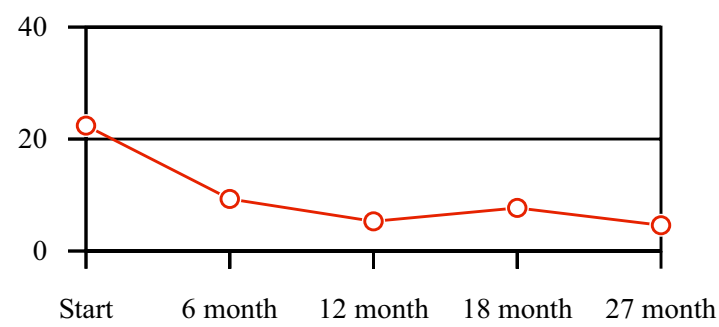

-O- Lat. Dev. (rms) mm

Surface rotation (rms) during the treatment time of 27 month

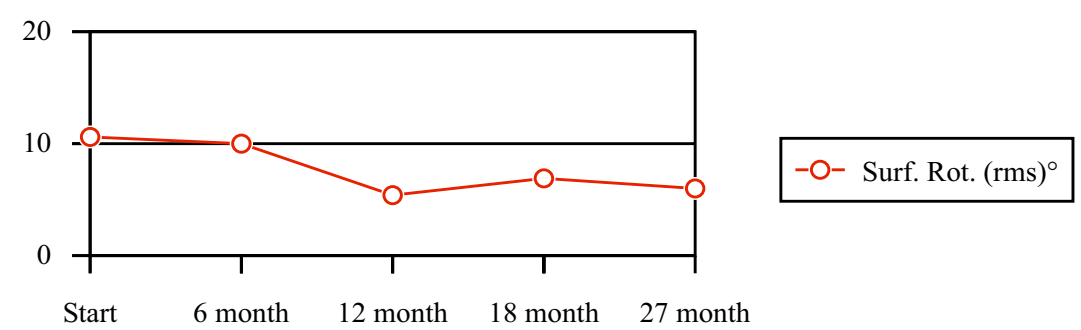

Figure 4

Clinical history of the patient as documented by angle of trunk rotation (Scoliometer) and surface topography (lateral deviation and surface rotation). On the top course of the thoracic ATR and lumbar ATR; on the bottom the course of lateral deviation and surface rotation during the time of treatment (27 Months). 

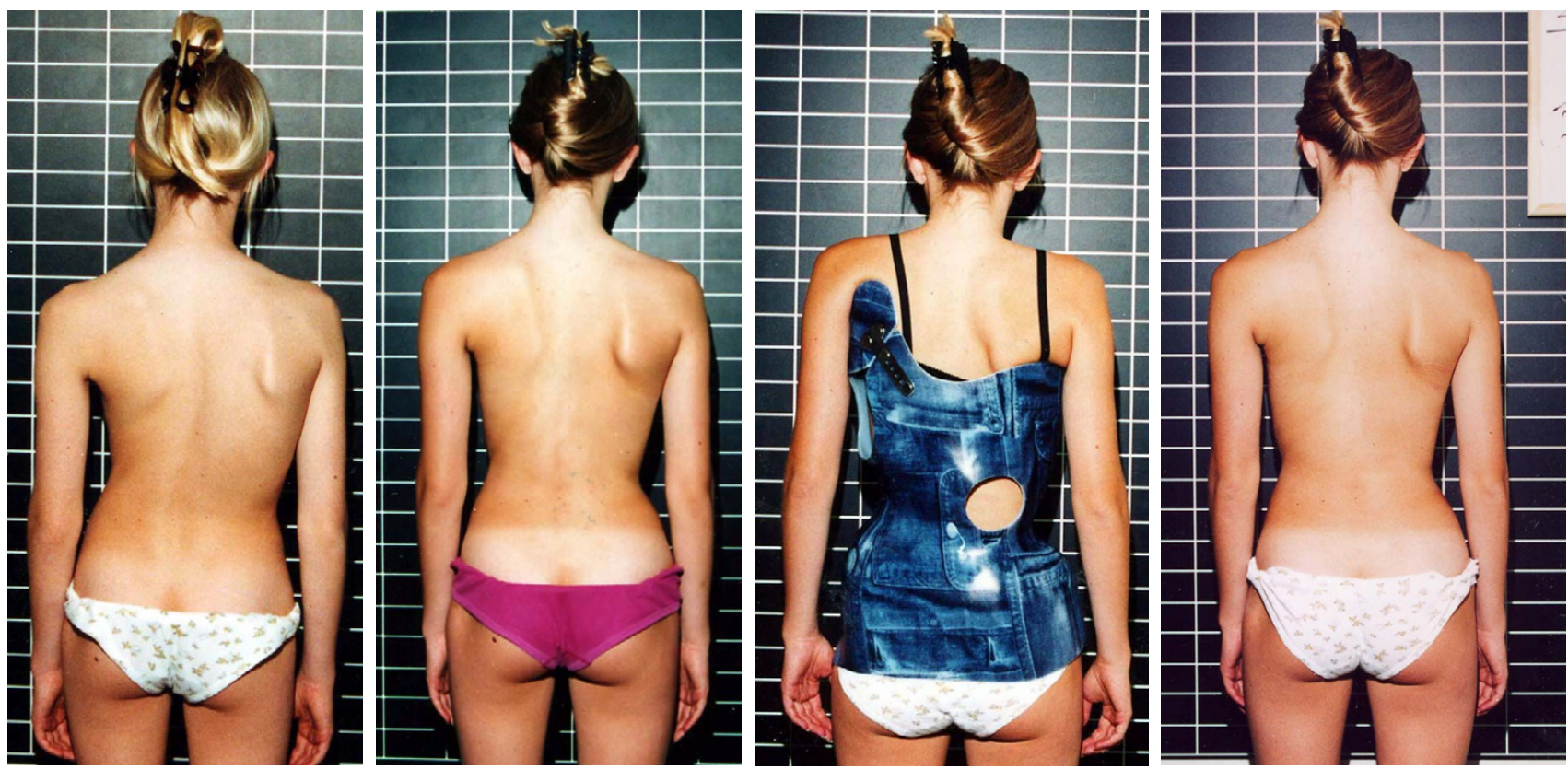

\section{Figure 5}

Clinical history of a patient with $45^{\circ}$ at the age of 13 and $27^{\circ}$ at the age of 16 after brace weaning. On the left the patient can be seen at the start of treatment, on the middle left clinically after one year of treatment, on the middle right in her second brace, and on the right after 36 months of treatment after weaning. A considerable cosmetic improvement can be seen comparing the picture at the start of treatment (left) to the picture two years after the onset of menarche (right) while the curve has improved $18^{\circ}$ Cobb at the same time.

\section{Cosmetic changes}

The cosmetic history of the patient is documented on figure 1 and 2.

\section{Radiological course}

The radiologic history of the patient is documented on figure 3.

The values describing the cosmetic changes can be seen in Additional file 1 and the history of those values are content of figure 4 .

\section{Discussion}

Long-term controlled studies indicate that spinal fusion for Adolescent Idiopathic Scoliosis (AIS), the largest of scoliosis populations does not lead to an improvement of lung function [25], to less pain [26], better „General Health" [27] and less degeneration [28]. So the only clear indication for spinal fusion in AIS patients and many other forms of scoliosis is severe deformity related stress [14], when the possible long-term risks of spinal surgery are respected [29].

Therefore the patient described in this case report can decide herself as to whether be treated conservatively or operatively. During clinical follow-up we were quite satisfied with the cosmetic improvements achieved although the initial Cobb angle was very high and after the followup x-ray we were quite surprised that the curve was progressive.

The first explanation for the increase of Cobb angle and the reduced rib-hump at the same time was geometry: If a curve is derotated it turns from a sagitto-frontal direction to frontal and therefore must show a bigger angle on the frontal x-ray. In that case, however the angle of rotation of the apical vertebra should improve at the same time. This is why the x-ray films have been re-evaluated and this time we also measured the rotation of the apical vertebra using the Raimondi device [30]. Interestingly the rotation angles showed to have increased as well.

One explanation for the cosmetic improvement could be change of rib shape. Obviously the Rigo-Chêneau brace is able to improve cosmetic appearance by changing the shape of the thorax when the curve itself is too stiff to be corrected by a brace, while in curvatures of less than $60^{\circ}$ with enough residual flexibility cosmetic improvements come along with improvements of the Cobb-angle (Fig. 5 

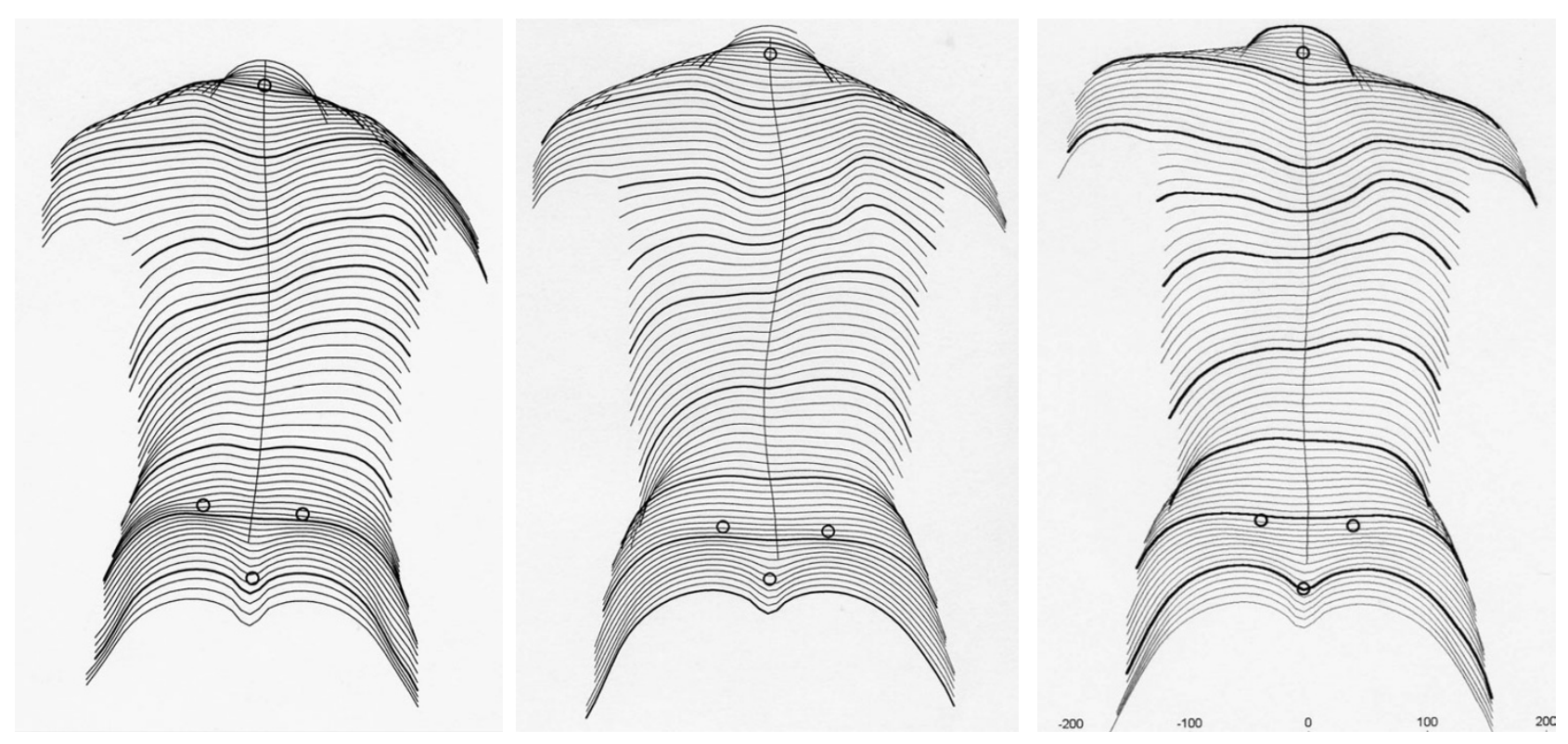

\section{Figure 6}

Clinical history of the patient as documented by surface topography (second year of treatment). On the left the patients reconstructed back can be seen at the start of treatment, on the middle picture I 2 months and on the right picture 36 months after weaning. A clear cosmetic improvement is visible when the initial surface reconstruction is compared to the last one on the right.

and 6) [22].

Another explanation could be that a reduction of decompensation in this case leads to a better cosmetical appearance, however this would not necessarily affect ATR.

Because during development girls usually gain weight (this patient did) a third explanation could be that the bones now are more masked by fat tissue than at the start of treatment and therefore the deformation is less visible, however the patient only gained $5 \mathrm{~kg}$ and this would not affect the deformation in the way demonstrated here.

The rib hump seems not to be wholly a secondary effect of scoliosis as the ribs are themselves asymmetric and the hump may continue to increase, especially in immature patients even following a secure surgical spinal fusion [31]. This phenomenon is already documented in literature [32-34]. This implies that the deforming forces are still working after the operation and especially on the thoracic cage.

It is believed that in idiopathic scoliosis, the rib hump is primarily deformed because the deformity of the thorax develops first and the deformity of the central axis (the spine) succeeds [35-37].
Therefore, the conservative treatment with a brace is cutting the chain of the detrimental cascade in a critical point and it is confronting the primary problem which is the deformation of the thoracic cage, which could be straightforwardly improved. Thus a possible explanation for the clinical improvement and the radiological progression, of the scoliotic patient who is described in this paper, could be the following based on the above observations. The offered Chêneau-Brace treatment in an already rigid spine could not affect the firm central axis (the spine, which passed a threshold point for correction, being stiff and deformed) but could affect the more flexible thoracic cage correcting its deformity. In other words the thoracic cage may play the role of an intermediate buffer for the pathologically acting forces. The changing pattern of the curve as it is mentioned in the text (see Results, Patient history) could also be a triggering factor in the above alternations.

Further studies are necessary to evaluate how to predict a radiological curve progression independently from the clinical measurements, because a long lasting brace treatment with a radiological curve progression may not be recognized as a successful treatment by the patient even if the clinical improvements are obvious. 


\section{Conclusion}

Conservative treatment with out-patient exercises, inpatient rehabilitation and the Chêneau brace may improve cosmetic appearance while the curve progresses radiologically. This could be explained by assuming that (1) a well designed Chêneau brace is able to improve cosmetic appearance by changing the shape of the thorax when the curve itself is too stiff to be corrected by a brace, that (2) reduction of decompensation leads to significant cosmetical improvements or (3) that the patient gained weight and therefore the deformation is masked. However, the weight the patient gained cannot explain the cosmetical improvement.

Conservative treatment with a certain standard of quality seems a viable alternative for patients with Cobb angles of $>60^{\circ}$ when surgical treatment is refused.

Specialists in scoliosis management should be aware of the fact that curve progression can occur even if the clinical measurements show an improvement.

\section{Competing interests}

The author(s) declares that he has no competing interests.

\section{Additional material}

\section{Additional File 1}

History of the patient as documented by angle of trunk rotation (Scoliometer) and surface topography (lateral deviation and surface rotation) and radiological data (Cobb angle and rotation of apical vertebra). This table summarizes the data of the patient.

Click here for file

[http://www.biomedcentral.com/content/supplementary/17487161-1-13-S1.xls]

\section{Acknowledgements}

The author would like to thank Robert Dallmayer, Ortholutions OHG, Rosenheim for providing the clinical pictures of the patient described. The author is also thankful to Theodoros B. Grivas, MD, Orthopaedic Department "Thriasio" General Hospital Magula, Attica, Greece for his helpful advice!

\section{References}

I. Klisic P, Nikolic Z: Attitudes scoliotiques et scolioses idiopathiques: prévention à l'école. Personal communication. Journées Internationales sur la prévention des scolioses à l'âge scolaire. Rome 1982.

2. Mollon G, Rodot JC: Scolioses structurales mineures et kinesithérapie. Etude statistique comparative et résultats. Kinésithér Scient 1986, 244:47-56.

3. Rigo M, Quera-Salvá G, Puigdevall N: Effect of the exclusive employment of physiotherapy in patients with idiopathic scoliosis. Retrospective study. Proceedings of the I I th International Congress of the World Confederation For Physical Therapy. London :|319-|321. 28 July - 2 August I99|

4. Weiss HR, Rigo M: Befundgerechte Physiotherapie bei Skoliose Pflaum, Munich; 2001 .
5. Pauschert R, Niethard F: Ergebnisse der krankengymnastischen Behandlung auf neurophysiologischer Grundlage bei idiopathischer Skoliose: Eine prospektive Analyse. In Wirbelsäulendeformitäten Band 3 Edited by: Weiss HR. Springer, Stuttgart; 1994:47-5I.

6. Weiss HR, Lohschmidt K, El Obeidi N, Verres Ch: Preliminary results and worst-case analysis of in-patient scoliosis rehabilitation. Pediatric Rehabilitation 1997, I:35-40.

7. Weiss HR: Skolioserehabilitation. Qualitätssicherung und Patientenmanagement Thieme, Stuttgart; 2000.

8. Weiss HR: The effect of an exercise programme on VC and rib mobility in patients with IS. Spine 1991, 16:88-93.

9. Weiss HR: Scoliosis-Related Pain in Adults - Treatment Influences. European Journal of Physical Medicine and Rehabilitation 1993, 3:91-94.

10. Weinstein SL: Natural history. Spine 1999, 24:2592-2600.

II. Lehnert-Schroth C: Dreidimensionale Skoliosebehandlung 6th edition. Stuttgart, Urban \& Schwarzer; 2000.

12. VOJTA V: Die cerebralen Bewegungsstörungen im Säuglingsalter 2nd edition. Stuttgart, Enke; 1976.

13. Mehta $\mathrm{MH}$ : Active auto-correction for early adolescent idiopathic scoliosis. J Bone Jt Surgery 1986, 68:682.

14. Goldberg C], Moore DP, Fogarty EE, Dowling FE: Adolescent idiopathic scoliosis: the effect of brace treatment on the incidence of surgery. Spine 200I, 26:42-47.

15. Emans JB, Kaelin A, Bancel P, Hall JE, Miller ME: The Boston bracing system for idiopathic scoliosis: Follow-up results in 295 patients. Spine 1986, I I:792-80 I.

16. Fernandez-Feliberti R, Flynn J, Ramirez N, Trautmann M, Alegria M: Effectiveness of TLSO bracing in the conservative treatment of idiopathic scoliosis. I Paediatr Orthopaed 1995, I5:|76-|8I.

17. Weiss HR: Standard der Orthesenversorgung in der Skoliosebehandlung. Med Orth Tech 1995, 5:323-330.

18. Mellerowicz H, Böckel T, Neff G, Frey R: Mittel- und Langzeitergebnisse der Behandlung von lumbalen Skoliosen mit dem Boston-Brace. 42. Annual Meeting of the Vereinigung Süddeutscher Orthopäden e.V., 28. April bis I. Mai, Baden-Baden 1994

19. Landauer F: Ist die Therapie mit dem Chêneau-Korsett wirksam? In Fortbildung Orthopädie 2. Die ASG-Kurse der DGO Edited by: Imhoff AB. Steinkopff, Darmstadt; 1999:31-38.

20. Thulbourne T, Gillespie R: The rib hump in idiopathic scoliosis: Measurement, analysis and response to treatment. J Bone Joint Surg, [Br] 1976, 58:64-7|

21. Rigo M: 3D Correction of Trunk Deformity in Patients with Idiopathic Scoliosis Using Chêneau Brace. In Research into Spinal Deformities 2 Edited by: Stokes IAF. IOS Press, Amsterdam; 1999:362-365.

22. Rigo M: Radiological and cosmetic improvement 2 years after brace weaning-a case report. Pediatr Rehabil 2003, 6:195-199.

23. Rigo M, Quera-Salva G, Puigdevall N, Martinez M: Retrospective Results in Imature Idiopathic Scoliotic Patients Treated with a Chêneau Brace. In Research into Spinal Deformities Volume 3. Edited by: Tanguy A, Peuchot B. IOS Press, Amsterdam; 2003:24I-245.

24. Weiss HR, Reichel D, Schanz J, Zimmermann-Gudd S: Deformity related stress in adolescents with AIS. Stud Health Technol Inform 2006, I 23:347-35I.

25. Pehrsson K, Danielsson A, Nachemson A: Pulmonary function in adolescent idiopathic scoliosis: a $\mathbf{2 5}$ year follow up after surgery or start of brace treatment. Thorax 200I, 56:388-393.

26. Danielsson AJ, Nachemson AL: Back pain and function 22 years after brace treatment for adolescent idiopathic scoliosis: a case-control study-part I. Spine 2003, 28:2078-2085.

27. Danielsson AJ, Wiklund I, Pehrsson K, Nachemson AL: Healthrelated quality of life in patients with adolescent idiopathic scoliosis: A matched follow-up at least $\mathbf{2 0}$ years after treatment with brace or surgery. European Spine Journal 200I, I 0:278-288

28. Danielsson AJ, Nachemson AL: Radiologic findings and curve progression 22 years after treatment for adolescent idiopathic scoliosis: comparison of brace and surgical treatment with matching control group of straight individuals. Spine 200I, 26:5I6-525.

29. Hawes $M$ : Impact of spine surgery on signs and symptoms of spinal deformity. Pediatric Rehabilitation 9 in press. 
30. Weiss HR: Measurement of vertebral rotation: Perdriolle versus Raimondi. Eur Spine J 1995, 4:34-38.

31. Weatherley CR, Draycott V, O'Brien JF, Benson DR, Gopalakrishnan $\mathrm{KC}$, Evans JH, O'Brien JP: The rib deformity in adolescent idiopathic scoliosis. A prospective study to evaluate changes after Harrington distraction and posterior fusion. J Bone Joint Surg $[\mathrm{Br}]$ 1987, 69: 179-182.

32. Dangerfield $P H$, Denton JL: The rib hump in infantile idiopathic scoliosis and its relationship to vertebral rotation and the Cobb angle. J Bone Joint Surg [Br] 1986, 68-B:679.

33. Burwell RG, Jacobs KJ, Polak FJ, Webb JK, Wojcik AS, Wythers DJ: The back hump after Cotrel-Dubousset, Harrington-Luque and Zielke instrumentation: a segmental appraisal of findings at one year, with implications calling for an international multicentre study of new instrumentations. In Sixth international Symposium on Surface Topography and Spinal Deformity Edited by: Albetri A, Drerup B, Hierholzer E. Gustav Fischer, Stuttgart; 1992:180-195.

34. Wemyss-Holden SA, Burwell RG, Jacobs KJ, Polak FJ, Mc Neill SA, Webb JK, Moulton A: Predicting the deformation of the rib cage around the fused spine after Cotrel-Dubousset instrumentation (CD) for adolescent idiopathic scoliosis (AIS). Proceedings of the Combined Meeting of the British Scoliosis Society and the Nordic Scoliosis Society, Newcastle-upon-Tyne, J Bone Joint Surg [Br] 1992, 74-B(SUPP I):. 5-6 June |99|

35. Grivas TB, Daggas S, Polyzois BD, Samelis P: The double rib contour sign (DRCS) in lateral spinal radiographs. Aetiologic implications for scoliosis? In Proceedings of the 2000 meeting of the International Research Society of Spinal Deformities Clermont, France. 23-26 May 2000

36. Grivas TB, Dangas S, Polyzois BD, Samelis P: The Double Rib Contour Sign (DRCS) in lateral spinal radiographs: aetiologic implications for scoliosis. Stud Health Technol Inform 2002, 88:38-43.

37. Grivas TB: Surgery is performed for cosmetic reasons. Stud Health Technol Inform 2002, 88: II6-122.

Publish with Bio Med Central and every scientist can read your work free of charge

"BioMed Central will be the most significant development for disseminating the results of biomedical research in our lifetime. "

Sir Paul Nurse, Cancer Research UK

Your research papers will be:

- available free of charge to the entire biomedical community

- peer reviewed and published immediately upon acceptance

- cited in PubMed and archived on PubMed Central

- yours - you keep the copyright
BioMedcentral 